\title{
Lenguaje y derecho. Una lectura teológico-política a partir de Walter Benjamin*
}

\author{
Recibido: 6 de junio de 2019 • Aprobado: 27 de septiembre de 2019 \\ https://doi.org/10.22395/ojum.v19n38a7
}

\author{
Alexánder Hincapié-García* \\ Bibiana Escobar-García***
}

\begin{abstract}
RESUMEN
El artículo presenta una lectura teológico-política de la relación entre el lenguaje y el derecho a partir de Walter Benjamin, como resultado de la investigación Los cuerpos de la excepción. Se argumenta que el derecho es el garante de la vida, pero solo como una captura que intensifica la inevitabilidad del mismo y no las condiciones para dar forma a una vida lograda. Las decisiones metodológicas corresponden a lo que Benjamin (2013 y 2015) nombra como montaje. Estas permiten, al menos, dos cosas: cuestionar los valores que promueve el liberalismo democrático en tanto que este aumenta el poder del derecho sobre la vida humana, y ensamblar distintas perspectivas analíticas de la obra de Benjamin para romper el efecto mítico del derecho sobre los hombres. La conclusión señala que han arrebatado del lenguaje sus cualidades simbólicas, metafóricas y alegóricas; de esto se sirve el derecho para aumentar la red de culpabilidad que extiende sobre la humanidad. Solo el lenguaje restaurado podrá devolver a los hombres la justicia y la capacidad de crear.
\end{abstract}

Palabras clave: derecho; lenguaje; culpa; violencia; mera vida natural.

Producto asociado a la investigación finalizada Los cuerpos de la excepción. Investigación financiada por la Universidad de Autónoma Latinoamericana y la Universidad de San Buenaventura, Medellín, Colombia. Código: FT-INV-O12. Acta de inicio firmada en octubre del 2014 y de cierre en febrero 2016 con el código INPR. 01. V1. Los autores participaron en calidad de investigador principal y coinvestigadora, en su orden.

* Estudios de pregrado en psicología y filosofía, magíster en Psicología, doctor en Educación. Docente titular, Facultad de Educación, Universidad de San Buenaventura, Medellín, Colombia. Áreas de trabajo: pensamiento judío, estudios literarios y pedagogía general. Correo electrónico: alexander.hincapie@ usbmed.edu.co. Orcid: https://orcid.org/0000-0001-6828-2786.

"** Licenciada en Pedagogía Reeducativa, licenciada en Educación Historia Filosofía, especialista en Desarrollo del Pensamiento Crítico Reflexivo Creativo, magíster en Educación y Desarrollo Humano, doctora en Filosofía. Jefa del Departamento de Pedagogía, Facultad de Educación, Universidad de Antioquia, Medellín, Colombia. Área de trabajo: pedagogía general. Correo electrónico: bibiana.escobarg@udea. edu.co. Orcid: https://orcid.org/0000-0003-2680-8115 


\section{Language and Law. A Theological-Political Approach Based on Walter Benjamin}

\section{ABSTRACT}

The article displays a theological-political approach to the relation between language and law based on Walter Benjamin as a result of the research titled Los cuerpos de la excepción (Exception's bodies). Here we state that law is the guarantor of life, but only as capture that intensifies the inevitability of itself and not the conditions for shaping an achieved life. The methodological conditions correspond to what Benjamin (2013 and 2015) names as a montage. These allow, at least, two things: questioning the values promoted by the liberal democracy as far as this one increases the power of law above human life, and assemble different analytical perspectives of Benjamin's work for breaking the mythical effect of the law on humans. According to the resulting conclusion, the symbolic, metaphorical and allegorical qualities of language have been taken away; and law takes advantage of this for widening the culpability net that it spreads upon humanity. Only a restored language might give back justice and creative capability to humanity.

Keywords: law; language; guilt; violence; mere natural life.

\section{Linguagem e direito. Uma leitura teológico-políitica a partir de Walter Benjamin}

\section{RESUMO}

Este artigo apresenta uma leitura teológico-política da relação entre a linguagem e o direito a partir de Walter Benjamin, como resultado da pesquisa "Os corpos da exceção". Argumenta-se que o direito é a garantia da vida, mas somente como uma captura que intensifica a inevitabilidade dele e não as condições para dar forma a uma vida bem-sucedida. As decisões metodológicas correspondem ao que W. Benjamin (2013 e 2015) define como "montagem". Estas permitem, pelo menos, duas coisas: questionar os valores que o liberalismo democrático promove, já que este aumenta o poder do direito sobre a vida humana, e "montar" diferentes perspectivas analíticas da obra de W. Benjamin para acabar com o efeito mítico do direito sobre os homens. A conclusão indica que foram extraídas da linguagem suas qualidades simbólicas, metafóricas e alegóricas; o direito se serve disso para aumentar a rede de culpabilidade que estende sobre a humanidade. Somente a linguagem restaurada poderá devolver a justiça e a capacidade de criar aos homens.

Palavras-chave: direito; linguagem; culpa; violência; mera vida natural. 


\section{INTRODUCCIÓN}

(...) no basta con tomar al mundo por testigo del mal comportamiento de cualquier camarero, sino que dicho mundo ha de sacar a los muertos de sus tumbas

(Benjamin, 2010a, p. 344).

Este artículo es resultado de la reflexión teórica de la investigación Los cuerpos de la excepción. El objetivo general puede entenderse como la urgencia por contribuir a la discusión acerca de las relaciones entre el lenguaje, el derecho y la vida humana. Como supuesto básico se propone que la relación del derecho con la vida humana es conflictiva por el predominio del primero sobre la segunda. Para expresarlo de manera directa, el derecho se presenta como el garante de la vida y, en esa medida, las formas jurídicas son los mecanismos indicados para su defensa. Sin embargo, el derecho es garante de la vida solo en los términos de una captura por la cual esta se reduce al límite de sus capacidades. Es una defensa que puede designarse como fallida en lo que concierne a marcos legales, políticos y culturales exiguos, cuando no contrarios, al logro de una vida humana creadora. El poder determinante de esta máquina antropológica — dígase su soberanía, si se plantea en términos teológicos - se nutre del resto del lenguaje que queda con la caída del hombre del paraíso. Esto quiere decir que el derecho degrada el lenguaje a su función comunicativa, sacrificando sus cualidades simbólicas, metafóricas y alegóricas que son la condición de toda actividad creadora.

La perspectiva teórica adoptada se retoma de la filosofía de Walter Benjamin. El recurso a este autor se relaciona con su inactualidad (Kozlarek, 2010; Romero Cuevas, 2010; Echeverría, 2010; Hincapié García, 2016a) o, tal vez, por su actualidad singular. Benjamin expone sus argumentos recurriendo de manera heterodoxa al pensamiento judío y al materialismo histórico. Este ensamble de fuentes, en apariencia opuestas, significa la adopción de conceptos que provienen tanto de la teología como de la filosofía y en esto radica su inactualidad o su actualidad singular. Es decir, Benjamin ofrece instrumentos teóricos de análisis que exceden los conceptos formales con los que habitualmente se reflexiona la praxis política en la modernidad.

En el ensayo "Tiempo mesiánico", Mancera (2005) discute la tesis IX expuesta por Benjamin (2012) en Sobre el concepto de historia. Para Mancera, Benjamin recurre en esta tesis al emblema de su mayor interés: el Angelus novus de Paul Klee. Este le permite mostrar, en primer lugar, la profundidad de la catástrofe histórica que consiste, en cierto sentido, en lo que el hombre como ser genérico ha hecho de sí mismo. Los tan apreciados logros culturales y civilizatorios producen espanto si se reconoce el sufrimiento que los ha hecho posibles. Allí donde se cultiva la idea de que la historia de la humanidad avanza hacia un futuro mejor, se niega que el costo de ese "avance" 
es el sacrificio de los inocentes. En segundo lugar, el Angelus novus se relaciona con las fisuras que iluminan las oportunidades fugaces de redención o de doblar el curso de esta catástrofe repetida. En otras palabras, muestra el resquicio por el cual una "leve fuerza mesiánica" puede hacer posible la entrada del Mesías. Este lenguaje, que de momento suena teológico, no es un ejercicio proselitista de algún sistema religioso en particular (menos del judaísmo: una religión opuesta al proselitismo por definición); se trata de introducir otras formas expresivas que interrumpan la cadena repetitiva de significados del lenguaje formalizado. Así, el Mesías no es un enviado del cielo, ni la "leve fuerza mesiánica" es la enervación de una dimensión más allá de la historia. En la filosofía de Benjamin, ambos conceptos indican que la revolución, entendida como la suspensión del estado de cosas actuales y por la cual el hombre es objeto de dominación, es una obligación ética y una necesidad histórica.

En un ensayo titulado Rememoración judía y tiempo mesiánico, cercano a Benjamin, Taub (2015) sostiene que la catástrofe histórica puede entenderse como un proceso de desmoronamiento o de destrucción del hombre. Las instituciones que él mismo inaugura no detienen dicho proceso, sino que, al contrario, lo enmascaran. No pocas veces la lucha por los derechos humanos o los llamados a la responsabilidad social dentro del orden del capitalismo, por ejemplo, sirven a la intensificación del proceso de dominio del hombre por el hombre. Sin embargo, es posible - y urgente- hacer del presente el escenario de la redención, esto es, hay que dar lugar al pasado, renovar el luto por lo perdido y devolver al lenguaje la capacidad para crear.

Ahora bien, el objetivo de este artículo no consiste en establecer, para la tesis IX o para cualquier otra, qué tan presente está Marx, el judaísmo, el romanticismo o el surrealismo en la filosofía de Benjamin, sino en reflexionar las oportunidades que este ensamble ofrece para analizar los acontecimientos históricos. Dicho de otra manera, ese modo de pensamiento gráfico, tan característico de Benjamin (2012), es lo que permite observar en lo discontinuo y en lo fragmentario, los proyectos malogrados e inacabados. De hecho, se puede pensar que estos solamente pueden expresarse por medio de "(...) imágenes dialécticas poseídas por el pathos y el secreto de la pequeñez" (Mancera, 2005, p. 144). Estos dos aspectos, sugiere Mancera, coinciden con la perspectiva judeocristiana de que en el desamparado se encarna el elegido. En otros términos, en el desamparado se actualiza el sujeto histórico de la redención. En el desecho, Benjamin advierte lo que está cargado de significado. Aquí se añadirá: en lo desechado se esconde una chispa revolucionaria. Estas declaraciones no se relacionan con la festividad posmoderna por la cual se declara el fin de los grandes proyectos (la metafísica, la historia, la filosofía o el humanismo) celebrando su ruina. Más bien, lo que se advierte es el peligro y el riesgo. Cadava (2014) sostiene que si las imágenes del pasado pasan fugazmente no es porque para el hombre sea imposible el acceso a la verdad, sino porque el pasado siempre está en peligro y en riesgo de 
desaparecer. La esperanza, si se puede aspirar a ella, solo será posible cuando las cualidades del lenguaje sean restauradas para actualizar el pasado.

El paradigma metodológico que permite la elaboración de este artículo adopta el método del montaje (Benjamin, 2013 y 2015). Este consiste en establecer vínculos entre distintas perspectivas, con el propósito de dar forma a interpretaciones críticas en torno al presente. El montaje como método se caracteriza por dos momentos. El primero, de tipo destructivo, se entiende como el trabajo de interrogar los valores del liberalismo democrático, toda vez que estos se revelan cómplices del estado actual de cosas. No se trata de mostrar dichos valores como la realización de la justicia, sino del poder del derecho para decidir sobre la vida humana. El segundo, de tipo constructivo, lejos de lo que pueda asociarse, no significa balizar el optimismo. Benjamin dirá que, por el estado actual de cosas, lo que resta es organizar el pesimismo, esto es, encender las alarmas para anunciar que el futuro no está asegurado y que el presente repite sin tregua la dominación que se imagina como parte del pasado. En todo caso, es un método cercano a una filosofía de la historia que no reclama sistema alguno, sino la posibilidad de investigar situándose en la urgencia del presente. Para Löwy (1997 y 2015), la filosofía de la historia siempre se representa a través de una rejilla que clasifica sus diferentes ejercicios en conservadores o progresistas. Walter Benjamin, por su parte, escapa a dicha rejilla en la medida en que su concepción de la historia se nutre de fuentes heterodoxas. Su orientación por lo desechado significa un giro radical al momento de concebir cómo se escribe la historia, pregunta que debe acompañarse con otra que interrogue por quiénes y desde dónde la escriben.

A continuación, el artículo se organiza en cuatro apartados. El primero se titula "Lenguaje: decadencia y restauración". En este se plantea el modelo teológico de la historia propuesto por Benjamin. En síntesis, se quiere resaltar la relación entre historia y lenguaje a propósito de su decadencia y restauración. El segundo apartado lleva por título "Derecho y vida". Como se puede intuir, se problematiza la relación entre ambos términos, al proponer que el derecho procede y conserva su vigencia por la reducción de la vida. "Karl Kraus: el hombre total, el demonio y el monstruo" es el título del tercer apartado. En este se expone un juego de imágenes, pensamiento gráfico como refiere Mancera (2005), con el que Benjamin enfrenta el derecho y el empobrecimiento del lenguaje. El hombre total, el demonio y el monstruo se constituyen en tres figuras que se alzan en franca lucha contra el derecho. Para finalizar, en las conclusiones se discute la desposesión sistemática de las cualidades del lenguaje.

\section{LENGUAJE: DECADENCIA Y RESTAURACIÓN}

Para Stéphane Mosès (1997), la cuestión central que puede rastrearse en toda la obra de Walter Benjamin se relaciona con la manera de hablar de la historia. De manera sumaria, la respuesta que Benjamin ofrece indica que la historia se narra. Por lo tanto, el espacio y el tiempo en el que vive el historiador son cruciales para transformar el 
pasado en historia. Sin embargo, dar vida a la narración histórica no es lo mismo que reconstruir el pasado, sino hacerlo visible a partir del presente y de la idea de futuro que cultiva el historiador'. Benjamin sostiene que la historia no se reconstruye, sino que se escribe. Por lo tanto, la crítica que toma su fuerza de la historia no puede disociarse de las relaciones entre el lenguaje y los estilos escriturales. Benjamin apunta a una tarea interpretativa que dista de la hermenéutica en la medida en que su interpretación no se realiza sobre textos a los cuales se les extrae el sentido, como si este estuviera "siempre ahí". Al contrario, si se sigue su filosofía, hay que anotar dos cuestiones. La primera informa que la interpretación imbrica el espacio y el tiempo del historiador, al igual que el lenguaje y los estilos de la escritura. La segunda indica que el compromiso crítico del historiador invoca su responsabilidad con la injusticia del pasado y la respuesta reparadora del presente.

Lo dicho hasta ahora, siguiendo a Stéphane Mosès, queda incompleto si no se plantea otra cuestión: ¿Cómo puede hacerse diáfano un caos de acontecimientos si la historia se construye cuando se narra y se escribe?, o bien ¿̇cómo hacer inteligibles los acontecimientos? Como ya se dijo, esto no supone revelar el sentido como si este aguardara agazapado para ser revelado. Tampoco persigue el propósito de Rickert (1971) en torno a la necesidad de un sistema para la filosofía de la historia, ocupado del domino de los valores y de las estructuras de sentido. Para la solución de estas preguntas, Benjamin formula tres modelos diferentes de la historia, aunque no drásticamente separados. El primero es el teológico (que será ampliado a continuación para alcanzar los fines de este artículo). El segundo es el modelo estético que puede rastrearse en El origen del 'Trauerspiel' alemán (1925). El tercero y último es el político, expuesto en la Obra de los pasajes (Das Passagen-Werk) y en el ensayo Sobre el concepto de historia.

Benjamin desarrolla el modelo teológico de la historia al menos en dos ensayos que se complementan al tiempo que se oponen. Se está hablando de Sobre el lenguaje en cuanto tal y sobre el lenguaje del hombre (1916) y de La tarea del traductor (1921). En el primero se concibe la historia como un proceso de decadencia escenificado en tres actos descritos dentro del pasaje bíblico de la creación. En el comienzo la palabra de YHWH crea al designar y lo que crea coincide con el nombre². Después, al hombre

1 Cabe anotar que futuro no indica aquí algún deber de predicción con el que se obliga al historiador. Hablar de la idea de futuro alude al para qué de la historia, un tema cercano a Nietzsche (2016), uno de los primeros que se interroga por si la historia puede tener utilidad para la vida. Nietzsche, como después lo hará Benjamin, se opone a que la historia (a la que se presume sin ninguna relación con el presente y el devenir de la vida y de los hombres) sea una actividad para debilitar el espíritu. Sobre el problema de la narración, aunado al de la experiencia, se sugiere el ensayo El narrador de Benjamin (2009a).

2 Bröcker (2014) hace notar que al igual que un palimpsesto, el lenguaje contiene un conocimiento que fue desfigurado por la razón discursiva que busca la validez de lo que se comunica y olvida que el lenguaje como fin es creación y realización. En el Génesis, YHWH crea las cosas al tiempo que las conoce. Para Bröcker el objetivo de Benjamin en su ensayo Sobre el lenguaje en cuanto tal y sobre el lenguaje del hombre es el de superar la diferencia entre esencia espiritual y materia, con el propósito de conocer lo absoluto en las cosas. 
le corresponde denominar. Podría decirse que este recibe el don de dar el nombre al descubrir la palabra con la que YHWH ha creado las cosas. Cuando Adán hace uso de este don con los animales se asiste al acto en que se funda el lenguaje original del hombre o, más bien, el acto en el que se muestra al hombre en el lenguaje original. Solo YHWH crea con la palabra y al hombre le es dado participar de la creación denominando. No obstante, el texto bíblico también narra su caída, la pérdida del don y la melancolía por el obligado abandono del paraíso en el que palabra y cosa coinciden. Esto último supone que uno de los efectos de la caída es el abandono del nombre o, en otras palabras, el olvido de su secreto 3 .

La caída trae consigo un tipo de conocimiento extraño, una paráfrasis incapaz de participar de la creación (Benjamin, 2010b): las palabras se vuelven estériles porque no tienen contenido alguno y no pueden dar imágenes al pensamiento. Al respecto, Cohen (1999) anota que, a fuerza de la repetición, el lenguaje aparece abigarrado a la parálisis del no poder decir. Errático, el hombre se aferra a la repetición como certeza, ignorante de la fuerza creadora del lenguaje. Este será un tema recurrente en la obra de Benjamin, para quien la realidad no está completa sin aquello que no ha podido llegar a ser (Mate, 2006).

Con la caída del hombre, el resto del lenguaje no alcanza para denominar lo que YHWH ha creado con la palabra. Queda para el hombre la sentencia. Aquí se produce un tipo de juicio que eleva la palabra sentenciadora como aquello en lo que el hombre puede reconocerse ${ }^{4}$. El juicio del hombre sobre el hombre no es una respuesta a la infracción de una ley, debido a que en el estado de unidad en el paraíso no había oposición entre lo bueno y lo malo o entre lo permitido o lo prohibido. Es en dicho juicio donde se establece el sistema de esta oposición. Situándose en este punto se puede comenzar a hablar del origen mítico del derecho en su separación de la justicia. Así se entiende que para Benjamin la crisis de la justicia es la del lenguaje. Sin ir más allá, el derecho la traiciona porque forja estructuras para juzgar dentro de lo que puede considerarse una lengua pública banal'5. Cuando el derecho sanciona dictando sentencia, se produce una separación radical entre el lenguaje de la justicia y el lenguaje del derecho. La sentencia no logra ocuparse de lo que el lenguaje antes se ocupaba, esto es, comunicar contenidos espirituales relativos a la justicia. Lo que queda es la tristeza de la naturaleza,

3 Dentro de la tradición judía el nombre guarda un secreto. La caída del hombre es la reducción del lenguaje a la función comunicativa. Esto implica que el hombre ya no puede acceder al secreto del nombre porque, incluso, ignora su presencia. Con la caída hasta el nombre es arbitrario.

4 Téngase por caso la sentencia que se habilita toda vez que se establecen grupos humanos diferenciados: judíos, homosexuales o ilegales. Dicho establecer supone, de entrada, un modo de percibir, gobernar y castigar con criterio diferencial.

5 Adviértanse los enunciados de la corrección política o, incluso, de ciertas formas de luchas minoritarias, como las de algunos feminismos, agenciando privilegios a través de concertar con la figura del Estado (Butler, 2011). Tampoco pueden omitirse los siempre renovados códigos de policía, denunciados por Foucault (2002) como pura administración de lo ilegal. 
sometida a la arbitrariedad de un lenguaje reducido a signos y rebajado a instrumento de comunicación. Ante la tristeza se alza el silencio o, en todo caso, un eco inaudible ${ }^{6}$.

Para Wohlfarth (1989), las consecuencias que Benjamin extrae del Génesis son más contemporáneas de lo que se imagina habitualmente. De hecho, lo que parece señalar es la "apertura a la historia" o el ingreso del hombre en ella: "Caída en el abismo de la subjetividad". El mal sin fundamento de una nada impotente. "(...) la subjetividad se devela, en toda su potencia arbitraria, como la impotencia misma. No es más que «vanidad»" (p. 160). Lo que puede interpretarse como la emancipación humana atrincherada en la subjetividad, no es otra cosa que el redoble de la fuerza de los dualismos y la exacerbación de toda división: el yo y el otro, el sujeto y el objeto o el hombre y la naturaleza. La caída (en la subjetividad) es "(...) la máquina infernal de la modernidad" (Wohlfarth, 1989, p. 161).

En La tarea del traductor, el otro ensayo antes mencionado, Benjamin (2010c) muestra la historia como un proceso de realización utópica. Podría decirse que la tarea del traductor es un proceso histórico ascendente en el que el lenguaje adámico es restaurado. Esta restauración es posible en tanto que el traductor no se ocupa de encontrar en la obra los contenidos comunicables, tampoco del acto de significar (das Meinen), sino en la forma de significar (die Art des Meinens). El traductor sabe que en el lenguaje comunicativo el hablante centra su atención en el mensaje, dejando de lado las cualidades simbólicas, metafóricas y alegóricas del lenguaje. Ahora bien, solo por dichas cualidades es posible la creación de un nuevo sistema de signos que no imita el lenguaje original de la obra, sino que favorece el avance del lenguaje hacia su meta utópica: el retorno al origen del lenguaje mismo. En este contexto, retorno no significa el regreso al paraíso, sino la restauración de todas las cualidades del lenguaje y con ello la posibilidad de una vida diferente, una vida lograda para los hombres.

Este proceso de retorno es calificado por Benjamin como mesiánico puesto que se realiza a través de la creación de lo nuevo y con esta creación el tiempo histórico se abre para que irrumpa la esperanza. Empero, la esperanza es posible a título de que los hombres puedan mirar hacia atrás; esto entraña que por la historia los hombres se descubren en el pasado y, de esta forma, como Benjamin dirá más adelante: la meta es el origen. No obstante, De Man (1989) sostiene que Benjamin va más allá de un simple humanismo subjetivista: en tanto la traducción consiste en hacer visible la relación del lenguaje con el lenguaje, el modelo teológico de la historia en su teoría de la traducción supone que la historia no pertenece a los hombres ni a su interioridad, sino al lenguaje y a su relación consigo mismo. Por lo tanto, el lenguaje ilumina para el hombre una historia que (no) le pertenece, pero sin la cual no puede verse a sí mismo. Abadi (2014), en una línea similar, sostiene que para Benjamin el lenguaje no pertenece a los hombres. Al contrario, el lenguaje es lo que se extiende sobre todas

Tema del que Sucasas (2015) se ocupa a propósito de Lévinas y la Shoah. 
las cosas, no hay nada en lo que él no participe. Aquí puede captarse una inversión importante: no es que el lenguaje sea un instrumento para el conocimiento, sino que todo conocimiento es posible en el lenguaje. Lo cual, si se sigue bien, incluye el conocimiento del hombre sobre el hombre.

En un cierre parcial, en esta visión de la historia el hombre aparece como un ser que habla, es decir, un ser de lenguaje. Por lo mismo, la mirada no está concentrada solo en los actos del hombre, sino en los signos que se crean a través de él: "El progreso o la decadencia de la humanidad ya no se medirán por la distancia que los separa de un bien original, sino por su distancia con respecto a una fase primera del lenguaje" (Mosès, 1997, p. 87). Lo radicalmente nuevo exige su creación en el lenguaje.

\section{DERECHO Y VIDA}

En 1921 Benjamin publica el ensayo Destino y Carácter con el propósito de establecer las fronteras entre estas dos nociones, liberarlas de los ámbitos de entendimiento que se las apropian (el carácter ligado a la ética y el destino a la religión) y superar la idea de que el carácter es un efecto del destino. Al separar estas nociones para comprenderlas mejor, Benjamin descubre que el hombre con carácter no tiene un destino; actúa y no está a la espera de la intervención de los dioses. Como dirá Galende (2009), el carácter es la luz inesperada que en un momento ilumina la plena libertad de un acto. Por su parte, el destino está unido a la desgracia como respuesta de los dioses a la culpa; en el destino el hombre no encuentra la felicidad como fruto de la vida inocente. Resulta problemático que como contraparte de la culpa no esté la felicidad para el inocente, pues esto significa que su sufrimiento es negado, su esperanza desoída y su vida condenada al fracaso. Benjamin permite concluir que si el destino no hace posible la felicidad, entonces ni siquiera puede ser pensado dentro del campo religioso (cuando este se plantea la redención), sino dentro del campo del derecho entendido como "un orden cuyos únicos conceptos constitutivos son la desdicha y la culpa y dentro del cual no hay camino pensable de liberación (pues algo que es destino es al tiempo también desdicha y culpa)" (Benjamin, 2010d, p. 178). Destino es el derecho que condena la vida humana reduciéndola a mera vida natural.

En el derecho la condena no se desprende de la culpa; al contrario, la culpa es un efecto de la condena. El destino es una red de culpabilidad que atrapa todo lo vivo y lo reduce a 'vida desnuda' (das Blosse Leben), es decir, la mera vida natural expuesta en su límite de precariedad. Una vida reducida a la sobrevivencia y obturada en las posibilidades de darse forma como vida lograda: un proyecto frustrado que no puede realizar su humanidad ${ }^{7}$. De esto se desprende que el destino nada le depara a esa mera

7 Es probable que, si del derecho se trata, se pueda hablar de un humanismo sin "humanidad" que, como puede inferirse, trabaja en contra de la "criatura viviente" en el hombre para introducir como eje de la vida política, cultural y económica a la persona jurídica (aquella que es producida en el despojo 
vida natural excepto el desenlace fatal. Para Benjamin (2010d) el sujeto del destino es indeterminable, es decir, el hombre no tiene un destino y es por esto que el juez determina el destino para el hombre al que se condena. Dicho en otras palabras: los hombres no tienen un destino. Más bien, el derecho crea un destino para los hombres y para estos el destino solamente puede darse como fatalidad.

A juicio de Benjamin, la culpa de la que se alimenta el derecho es uno de los elementos constitutivos del destino al lado de la desdicha. Este destino, visto desde una referencia mítica, señala que la vida del hombre está sometida/condenada a la fatalidad sin esperanzas de redención. Nótese que el destino se ensaña contra el hombre en el ejercicio por el cual este no puede ser más que remitido a lo que el derecho decide. Benjamin establece una distinción entre el mundo de lo sagrado y el mundo de la ley, y en esta distinción separa dos nociones: criatura viviente y persona. La formalización que el derecho hace de la mera vida natural es lo que se entiende en términos jurídicos como la persona (Galende, 2009). Ahora bien, si la persona es la que el derecho puede criminalizar, reducir y formalizar, la criatura viviente es la que se opone al proceso de producción por el derecho. La criatura, si se permite la interpretación, es el hombre desnudo que se hunde en el secreto de la restauración del lenguaje ${ }^{8}$.

El derecho establece que la culpa y la desdicha son las leyes del destino. Por eso para Benjamin el derecho es el resto de un orden demoniaco maligno, en el que las leyes jurídicas determinan las relaciones posibles entre los seres humanos y del hombre con aquello que lo excede (YHWH y la naturaleza). En esta medida, el derecho no es la defensa de un orden ético. Al contrario, por el derecho el ser genérico del hombre es negado (Marx, 2008). Benjamin, por su parte, infiere que en el derecho ningún orden ético puede restablecerse (sea el de la costumbre o el de la justicia). Antes bien, el hombre entregado al derecho se arrastra y revuelca en la ruina de toda ética. Cuando el hombre clama al derecho por la recuperación de la vida moral, el derecho responde displicente con el procedimiento de la ley.

Al establecer que el derecho no es una simple operación que somete la vida del hombre, sino que la establece y la produce mediante la culpa y la desdicha, lo que sigue

de sus fuerzas). Para comprender mejor este concepto se recomienda el trabajo de Garcés-Gómez y Escobar-García (2010). También es interesante el trabajo de Piñeres-Sus (2017) para quien resulta necesario reflexionar si, a fuerza de tanto humanismo que insiste en preguntarse cuál es la naturaleza del ser humano y en qué consiste su lugar central en el mundo, lo que se prepara sistemáticamente es la destrucción de los hombres que quedan por fuera de lo que dichas preguntas alcanzan a representar. En otras palabras, la pregunta por la humanidad trabaja en contra de los hombres que no pueden anexarse a la respuesta.

8 Siguiendo a Benjamin, se puede afirmar que existen dos actividades que dirigen el lenguaje hacia su meta utópica: la poesía y la traducción. El poeta y el traductor poco saben de patrias y de lenguas maternas. La restauración de las cualidades del lenguaje los conduce a verificar su (in)humanidad. En la poesía y la traducción descubren que, después de la caída, si se trata del lenguaje, el hombre es siempre un extranjero. 
es preguntarse por la relación entre el derecho y la violencia. Para ello es importante recurrir a Hacia la crítica de la violencia. En este ensayo, lleno de categorías teológicas como destrucción, juicio final, reconciliación, mesianismo o catástrofe (Taub, 2013), Benjamin (2010e) se pregunta si en un mundo constituido por el derecho podría no existir la violencia. En efecto, las categorías teológicas utilizadas no son arbitrarias en la medida en que la pregunta por las relaciones entre el derecho y la violencia excede cualquier análisis formal de la filosofía del derecho. Con dichas categorías Benjamin muestra el carácter maligno del problema. Por ello, la pregunta es abordada aplicándose a tres tareas: la primera consiste en señalar que la violencia mítica es una manifestación de la existencia de los dioses, no es un medio para el logro de fines, sino expresión de su poder. El castigo de los dioses no se ejerce para restituir el derecho, sino porque se ha desafiado lo que el destino les reserva a los hombres. En otras palabras, la violencia del derecho no se ejerce para garantizar una vida lograda para el hombre sino para prolongar el poder de las formas jurídicas.

En Hacia la crítica de la violencia, Benjamin (2010e) analiza el mito de Níobe para apuntar que los dioses fundan por la violencia un nuevo derecho al aniquilar a los hijos de la mortal como castigo9. Esto quiere decir que no se castiga la violación de un derecho ya existente, sino que se constituye uno nuevo que no puede renunciar a la violencia. De lo anterior se colige que fundar el derecho es equivalente a fundar el poder que se manifiesta de manera aterradora en la culpa que se siembra e intensifica:

Aunque conduzca a los hijos de Níobe a una muerte sangrienta, respetará la vida de su madre, que queda (siendo incluso más culpable que antes, debido a la muerte de sus hijos) como la portadora eterna y enmudecida de la culpa, mojón entre los humanos y los dioses. (Benjamin, 2010e, p. 200)

\footnotetext{
Níobe era hija de Tántalo y esposa de Anfión (un músico dotado que había ayudado a construir las murallas de Tebas atrayendo a las rocas con el sonido de su lira). Los esposos llegaron a ser reyes de esta ciudad. Níobe tenía un único motivo de orgullo: había dado a Anfión siete hijos y siete hijas en los que basaba toda su felicidad. En una ocasión, cuando se celebraban los ritos de adoración para Latona y sus dos hijos, Apolo y Artemisa, Níobe canceló la ceremonia porque consideró inútil adorar a seres que no podían ser vistos cuando ella, que podía ser vista no era adorada. Además, ella era más dichosa que los dioses con sus hijos. El pueblo de Tebas la obedeció y los rituales quedaron incompletos. Latona oyó las palabras de Níobe y su venganza no se hizo esperar. En Tebas se celebraban los juegos atléticos y en ellos participaban los hijos varones de Níobe y Anfión. Apolo, obedeciendo a su madre, tomó su arco y sus flechas y mató uno a uno a los jóvenes. Advertida por los gritos de la gente, Níobe llegó al campo donde se encontraban los cuerpos de sus hijos. La rodeaban sus hijas que compartían con ella su dolor. Pero una a una, ellas también fueron cayendo sin vida por los dardos que lanzaba Artemisa. Abrazando a la más pequeña, mientras las demás yacían a su lado, Níobe en vano, clamó la piedad a los dioses. Tomó en sus brazos el cuerpo de la más pequeña de sus hijas y huyó hacia el Asia Menor. Los restos de su familia permanecieron insepultos durante nueve días, pues los dioses habían transformado en piedra a los habitantes de Tebas. En el décimo día los propios dioses les dieron sepultura. Níobe vagó con el cadáver de su hija hasta llegar al monte Sípilo. No pudo avanzar más pues su dolor no le permitía moverse. El viento no agitaba su pelo, sus ojos quedaron fijos en el rostro de su hija, la sangre dejó de fluir dentro de ella. Se transformó en una roca, pero sus ojos continúan emanando lágrimas.
} 
Si el derecho es lo que establece y produce la vida, entonces este no crea condiciones para la existencia de los hombres más allá de la precariedad, esto es, no hace posible liberación alguna. El derecho, que es violencia mítica, crea a la persona al borde de la desgracia por existir. Ante esto, Benjamin reclama oponer la violencia divina a la violencia mítica. Siempre contrarias, la segunda es el fundamento del derecho en tanto traza fronteras e inocula la culpa. Entretanto, la violencia divina aniquila el derecho puesto que destruye las fronteras y redime al hombre de toda culpa (deuda) ${ }^{10}$.

La segunda tarea que Benjamin se propone con el ensayo Hacia la crítica de la violencia tiene que ver con el modo en que el derecho establece y produce la mera vida natural. Benjamin (2010e) enfrenta la propaganda humanista que enaltece la sacralidad de la vida y prescribe que esta sea respetada y valorada, pasando de largo que todo resulta fútil si la vida de la que se habla no tiene a su alcance las condiciones materiales y morales suficientes para oponerse a su precarización. Una vida lograda es aquélla que se vive y se crea por fuera de un derecho que la culpabiliza. Al confundir el derecho con el reino de la justicia, se petrifica la vida y el hombre no puede más que gravitar en el ciclo de la culpa y la desdicha. Contrario a cualquier argumento que se exhiba, para el derecho todo hombre es culpable porque lleva una señal, no de lo que hace, sino de lo que podría llegar a hacer. No es por la religión por lo que el hombre nace culpable, es por el derecho que así deviene, en tanto ninguna vida humana puede realizarse si no es en las formas jurídicas. Esto queda demostrado en el hecho de que toda relación entre los seres humanos queda compelida a responder ante el derecho ${ }^{11}$. En este registro, el derecho se ofrece a sí mismo como la única solución posible para discernir sobre la vida humana. En efecto, lo hace reduciendo las condiciones de su existencia ${ }^{12}$.

10 Para Buck-Morss (2001) las biografías intelectuales sobre Walter Benjamin organizan su obra delineado tres grandes etapas, a saber: la etapa teológica y metafísica, en la que se destaca su amistad con Gershom Scholem; la etapa marxista, cuando entra en relación con Bertolt Brecht y la etapa de su exilio en París, en la que dependió en gran medida del apoyo de Theodor Adorno. El ensayo Hacia la crítica a la violencia, si bien se corresponde temporalmente con la etapa teológica y metafísica, al enfrentar la violencia mítica (entendida como derecho) con la violencia divina (entendida como redención), lleva consigo el eco de Marx allí donde este imaginó que en el comunismo lo que ha de imperar es la asociación libre entre los hombres (no el derecho). Para Marx (2007 y 2008), esto significa la restauración de los vínculos del hombre con el hombre y del hombre con la naturaleza. Para Benjamin, como aquí se expone, tiene que ver con el lenguaje, la escritura, la historia y la lucha contra las formas jurídicas.

11 El matrimonio, objeto de disputa entre liberales y conservadores, progresistas y reaccionarios, resulta la expresión más patética. En el estrado donde los amantes juran amarse se levanta una sombra aterradora: la forma jurídica como amenaza implícita que el uno y el otro, de manera recíproca, se prometen en cuanto a los bienes, el cuerpo y el desamor. Para un estudio completo sobre este tema se recomienda 'Las afinidades electivas' de Goethe de Walter Benjamin (2010g). Es un ensayo dedicado a Jula Cohn, una de las mujeres que Benjamin amó.

12 Vale la pena hacer resonar con Butler (2009), la pregunta por el modo con el que se define aquello que tiene valor como humano, qué vida se considera digna de ser vivida, cuáles no son vidas para ser lloradas, reconocidas y legibles políticamente. Más importante aún, preguntarse de qué manera se puede vivir una vida reconocible. De estas preguntas la autora desprende que si los términos del poder 
Con la tercera tarea, Benjamin (2010e) afirma que una crítica de la violencia es la filosofía de su historia, esto es, la violencia recorre la historia y se relaciona de manera íntima con el derecho y con la justicia. La relación a la que se alude no es causal en la medida en que, como apunta en Destino y carácter (2010d), un nexo de significado no procede por causalidades. La violencia instaura y conserva el derecho y esto significa que la violencia ejercida no necesariamente busca destruir la vida en su totalidad. Tal vez por un criterio económico, el objeto sea su preservación en los límites biológicos (mera vida natural), para ser administrada en la culpa y la desdicha. Aquí se alza una extraña paradoja ya antes señalada: la vida se forma (produce) en el instante de su negación (deproducción).

Para ampliar esta paradoja hay que recurrir a Giorgio Agamben (1998). Este sostiene que el derecho constituye la vida en su captura, no para sancionar una conducta sino para intensificar la culpa del ser viviente. Como ya se expresó, por el derecho el hombre llega a la vida culpabilizado en el sentido originario de estaren-deuda. Para Agamben, la culpa no es un término que haga referencia a la transgresión por la que se establece lo lícito y lo ilícito, sino que se dirige a la pura vigencia de la ley. Esta afirmación requiere remitirse, al menos, a las primeras páginas de Homo Sacer.

Agamben aborda esta figura del derecho romano arcaico para hacer notar la importancia del problema tratado hasta aquí: derecho y vida. En primer lugar, expone el modo a través del cual el poder soberano captura la vida por exclusión. Adviértase la función que representa el hombre sagrado: aquel al que puede darse la muerte al tiempo que es insacrificable (Agamben, 1998). Si se recurre a un ejemplo casuístico, la confianza del liberalismo en torno a los derechos humanos coincide con el sacrificio de los inmigrantes ilegales en Europa y Estados Unidos. Por un lado, las potencias mundiales enarbolan un humanismo tísico (para usar una expresión de Benjamin) y, por el otro, las mismas potencias dan la muerte a través de la política internacional. La soberanía queda entendida como la base de la captura de la vida, esto es, el poder soberano capaz de presentar como legal, sin mucha contrariedad moral, lo que no debe ser legal: dar la muerte. En esa suspensión de los derechos (para algunos), la vida situada por fuera de lo jurídico empieza a coincidir con el espacio político. La vida biológica y la vida política (el hecho y el derecho) ven diluirse las fronteras que

definen quién está autorizado para ser reconocido como un sujeto político o de derecho, es porque el sujeto no es una precondición de la política, sino un efecto diferencial del poder: unas vidas legibles en el reconocimiento y otras en su precarización. ¿Pero, qué puede entenderse por precarizar una vida? La autora subraya con esta expresión que cualquier elemento vivo corre el riesgo de ser suprimido. La consecuencia es drástica: nada garantiza la vida. Aunque el derecho anuncie que se tienen derechos y los órdenes políticos deban garantizarlos, se encuentran millones de vidas expuestas por el capitalismo a sufrir enfermedades, pobreza, hambre, falta de protección, exclusión y marginación. Una vulnerabilidad maximizada porque ciertas vidas están sujetas a la violencia de los mercados económicos y de los Estados a través de su relación con el derecho. 
las separa terminológicamente en la concepción griega, para dar lugar a una mera vida natural que se constituye en sujeto y objeto del ordenamiento político ${ }^{13}$.

En segundo lugar, Agamben (1998) refiere que el poder soberano, al decretar la excepción, garantiza la vigencia del derecho: "No es la excepción la que se sustrae a la regla, sino que es la regla la que, suspendiéndose, da lugar a la excepción y, solo de este modo, se constituye como regla, manteniéndose en relación con aquella" (p. 31). La soberanía decreta el estado de excepción, no para imponer orden en el caos, sino para suspender el orden jurídico reinante mediante un decreto o ley. Se desprende un contrasentido: el estado de excepción no es una situación de hecho pues es la norma la que lo estatuye, pero tampoco es de derecho debido a que este se suspende para poder decretársele.

De lo anterior se deriva que la soberanía, el estado de excepción y el derecho están claramente relacionados; esta relación es de creación, conservación y dependencia recíproca. Dicho de otro modo, al decretar un estado de excepción, se establece una situación de peligro inminente con el fin de conservar vigente la necesidad del derecho. Reducir al hombre a mera vida natural o dar muerte a quien es insacrificable es un ejemplo de ello. El resultado es contradictorio: el hombre reducido a mera vida natural no queda por fuera de la ley, sino "que es abandonado por ella, es decir, que queda expuesto y en peligro en el umbral en que vida y derecho, exterior e interior se confunden" (Agamben, 1998, p. 44) ${ }^{14}$.

Recuérdese que en la Modernidad la vida se convierte en el centro de la política (geo)estatal, gracias a esa zona de indiferencia que se establece entre vida y derecho. Si Kant (2003) en su pedagogía informa que el hombre no es más que lo que la educación haga de él, en la estela de Benjamin, Agamben corrige esta determinación al demostrar que se está al borde de que el hombre no sea más que lo que por derecho se decide. En otras palabras, el derecho protege la vida acrecentando y fortaleciendo el tiempo y el espacio de la muerte (Taub, 2008).

13 Según Agamben (1998), los griegos antiguos no disponen de un único término para designar la vida tal y como se entiende en la Modernidad. Usan dos términos diferentes tanto en lo semántico como en lo morfológico. El primero, zoé, expresa lo que significa el simple hecho de vivir. La zoé es común a todos los vivientes, es decir, a los animales, los dioses o los hombres. El segundo, bios, hace referencia a la manera de vivir de un grupo o de un individuo.

14 Curiosamente, en Los estados de excepción en el régimen constitucional colombiano, Tobón-Tobón y MendietaGonzález (2017) sostienen que la Constitución política de Colombia de 1991 representa un giro copernicano con respecto al anterior régimen, puesto que crea los instrumentos para limitar el recurso al estado de excepción. Este planteamiento puede resultar apropiado en términos de derecho, pero, no obstante, falla en términos antropológicos y políticos al plantear, de manera optimista, que el derecho vence lo letal que el mismo derecho introduce en la producción y deproducción de lo humano. 


\section{KARL KRAUS: EL HOMBRE TOTAL, EL DEMONIO Y EL MONSTRUO}

En 1928, previo a un ensayo más extenso que lleva el mismo título, Benjamin publica Karl Kraus en la revista de Ámsterdam. A su juicio, en el escritor austriaco se da la incursión más grande de la literatura halájica dentro de la lengua alemana. Halájico quiere decir relativo a la ley judía o conforme a la Torá. Benjamin recurre aquí a la imagen del judaísmo para desbrozar, desde un comienzo, el giro que tomará su argumento: el problema a tratar tiene que ver con el lenguaje, el derecho y la vida. En concreto dice que "no se entiende nada de este hombre mientras no se comprenda que, para él, todo (sin excepciones, el lenguaje y la cosa) se desarrolla con necesidad, siempre, en la esfera del derecho" (Benjamin, 2009b, p. 234). Es importante advertir que, en la declaración, el lugar desde donde se enfrenta el derecho es el que se abre por la incursión de una cierta teología judía en la vida política europea. Kraus es "la oración más intensa, la más firme plegaria por la redención que hoy puede salir de unos labios judíos" (Benjamin, 2009b, p. 235).

Karl Kraus (1874-1936) dirige la revista Die Fackel (La Antorcha) entre 1899 y 1936. Desde allí lanza prolíficos ataques en contra del periodismo, el derecho y la actividad política en general (a la que desnuda en su corrupción). Radicaliza sus posiciones con la defensa de los derechos de los homosexuales y de las prostitutas. En 1931, Benjamin publica un nuevo ensayo sobre Kraus y lo organiza a través de tres figuras: el hombre total (Allmensch), el demonio (Dämon) y el monstruo (Unmensch). Puede deducirse que Kraus las encarna y con ellas da forma a un odio vital por oposición al odio moral. Mientras este último es una lengua que juzga y sanciona, el odio vital es destructor al apuntar directamente en contra de dicha lengua. Kraus fustiga el uso del lenguaje como mero instrumento de comunicación y su degradación en una lengua (opinión) pública banal, saturada de fetiches, lugares comunes y repeticiones. Un uso común tanto en el periodismo como en el derecho. Se irá por partes con las tres figuras antes mencionadas.

En el hombre total (Allmensch), la primera de ellas, Benjamin se refiere al rechazo visceral de Kraus por la expresión opinión pública. Para este, la opinión es algo privado; a lo público corresponde el saber juzgar. Sin embargo, la prensa crea una "opinión pública" sin capacidad de juicio, pero autorizada desde una actitud irresponsable y caprichosa. En la opinión pública reina un lenguaje lleno de lugares comunes, vacío de contenido e inescrupuloso: frases ya hechas e insípidas, rebosantes de arbitrariedad. La opinión, declara Benjamin, es la falsa subjetividad que adopta la forma de una mercancía, un lenguaje incapaz de "sacar a los muertos de sus tumbas" (Benjamin, 2010a, p. 344). Es una lengua que al hablar de justicia no puede ser más ajena a ella.

Un rasgo del carácter del hombre total es el tacto como criterio teológico que le permite estar abierto a los acontecimientos y responder a ellos excitando la polémica. Polemizar es para Kraus un arte en el que entran en juego el silencio, el conocimiento 
y la presencia de espíritu que no responde las preguntas de su oponente, sino que devuelve la cuestión por la pregunta verdadera o la pregunta por la verdad. Con este comportamiento, que va en contra del decoro y las buenas costumbres, fustiga la idea de que el tacto es dar a cada uno lo que le corresponde o actuar con prudencia en el sentido de Kant (2003). Por el tacto, el hombre total da la cara a las situaciones sociales que, naturalizadas, precarizan las vidas juzgadas como indignas (aquí se comprende la defensa de los homosexuales y de las prostitutas). Para Benjamin, siguiendo a Kraus, no es posible respetar las formas establecidas y, al mismo tiempo, declararse en defensa de la justicia.

La segunda figura es el demonio (Dämon). La vanidad es expresión de su esencia. Lograr la profundidad que evita lo banal y auto exponerse de manera despiadada, es el modo en que esta figura se relaciona con el lenguaje. Kraus se entrega como lo que es: aquello que hace sufrir. Convierte las debilidades y los padecimientos en un tributo a los nervios y al cuerpo. Intensifica sus fuerzas y lucha por el vivir pleno de la vida, a pesar de que esto suponga el sufrimiento. La relación de Kraus con la escritura es teatral "porque tan solo ella le ofrece mil oportunidades para exhibirse bromeando, importunando, amenazando" (Benjamin, 2010a, p. 354). El demonio aniquila a su enemigo porque es un experto de la sátira y en ese estilo radica su crueldad. Kraus es el zelote que levanta un proceso en contra del orden jurídico, no como el triste sujeto de derechos, ni con la actitud grotesca del activista liberal que cuestiona este o aquel artículo de la ley. Kraus dirige su ataque contra toda la esfera del derecho pues, como ya se ha dicho, esta no es más que la traición de la justicia. Rehúsa entablar cualquier tipo de pacto con el derecho. iEn eso es experto el reformista liberal!

El derecho para Kraus es un abismo destructor. No puede ser justicia porque este es la reducción de la vida a su condición más básica. La justicia comparte su ámbito con el lenguaje. Si estos dos van juntos, la banalización del lenguaje, los clichés del periodismo y la palabra sancionadora del derecho, son expresiones de la traición a la justicia. Por ello, resistirse al abismo destructor consiste en liberar el lenguaje, escribir en contra del orden decretado, usar la historia para despertar a los muertos y esforzarse por crear una vida opuesta a la identidad socialmente asignada. Kraus representa la orientación por el sexo y el espíritu puro, es decir, por la oscuridad y lo nocturno (sexo) y la compasión por las víctimas y los acusados (espíritu).

En la estela de Kraus, las luchas políticas son fulminantes y viscerales. Nótese la lucha en contra de los códigos policiales que, además de promover la ilegalidad, pontifican sobre la moralidad de la conducta sirviéndose de contenidos que no expresan más que la hipocresía social. En otras palabras, los códigos de policía se sirven de la hipocresía social con la bendición del derecho. Adviértase, por ejemplo, que acusar a un hombre de delitos contra la moral no es otra cosa que el proceso mediante el cual la falsedad del derecho y la inmoralidad generalizada se imputa, de manera individual, 
a un acusado. A este, como a una víctima expiatoria, se le impone responder por la mala consciencia de la humanidad entera en nombre de las "buenas costumbres". Ahora, no es que Benjamin exponga que la figura del demonio encarna lo puro. Antes bien, ella es parte constitutiva del ámbito de la purificación. En la figura de demonio se encuentra la fuerza para resistir la lengua pública banal de la época y atender el grito de quienes esperan ser redimidos. La desobediencia civil y el rechazo al espacio público gestionado por la policía son dos expresiones del demonio que Kraus encarna.

La tercera figura es el monstruo (Unmensch). El rasgo del carácter que lo estimula es la sátira con la que devora a sus enemigos, en particular los derechos humanos y el ideal de humanismo que en ellos subyace ${ }^{15}$. Con anterioridad, Kraus sentencia que los derechos humanos son el juguete con el que todos los adultos juegan y, por lo mismo, todos luchan para que no les sean arrebatados. El monstruo dirige su sátira a la charlatanería de la prensa que trae como efecto la disolución de los límites entre lo público y lo privado en los que se destruye la noción de libertad proclamada por la Revolución Francesa. La charlatanería aturde a los hombres, atrofia su capacidad crítica, los hace dóciles y frágiles: los enlista para el mercado y el consumo. Para oponerse, el monstruo invoca la rima que acerca a la poesía y con ella a lo más elevado del lenguaje: el nombre. Se confirma que la relación del monstruo con el lenguaje se fundamenta en una creatividad que actúa para alimentar los nervios, el placer y el cuerpo que se resiste al trabajo impuesto y al control de la vida corporal. El monstruo es el mensajero del disfrute que destruye la frase hecha y que da paso a otra destrucción: la de la justicia divina que viene a poner fin a las ambigüedades construidas por el derecho. La insistencia en el lenguaje es la reafirmación judía de que este es el proscenio de la santificación del nombre.

Tal vez, uno de los rasgos más importantes con los que Benjamin caracteriza al monstruo estriba en que es opuesto al superhombre (Übermensch) de Nietzsche. Para Sax (2014) esta oposición no solamente refleja la conflictiva relación de Kraus con la filosofía de Nietzsche, sino también una oposición necesaria. De la destrucción del superhombre, Kraus emerge como figura de un real humanismo ${ }^{16}$. Aquí el monstruo es el no-hombre (criatura-niño) que enfrenta al superhombre. Recurriendo a una inferencia que el mismo Benjamin proporciona, el enfrentamiento se libra en el lenguaje y con el recurso a la cita. De cierta forma, podría especularse que Benjamin se enfrenta a Nietzsche, a través de Kraus, de manera oblicua. Benjamin y Nietzsche son dos adversarios demasiado

15 Los derechos humanos no son la corrección del mundo moderno ni la prevención suficiente en contra del mal moral. En concreto, si la existencia del hombre depende de una política convertida en derecho, no es extraño plantear que el mal moral siempre encontrará al hombre expuesto para su destrucción (Hincapié-García, 2014). Para un análisis de la cuestión del mal vale la pena remitirse al trabajo de Ricardo Forster (2014).

16 Al finalizar su ensayo sobre Kraus, Benjamin (2010a) muestra el parentesco del humanismo real con la emancipación humana expuesta por Marx en La cuestión judía. Para un estudio sobre las posibles afinidades electivas de Benjamin con respecto a Marx se sugiere el trabajo de Hincapié-García (2016b). 
eminentes para enfrentarse en un duelo que pudiera significar la muerte de uno de ellos. Ambos son extemporáneos y por ello consiguen renovar los instrumentos para la praxis política. Para Wohlfarth (2016), Benjamin y Nietzsche son extranjeros interiores que se cruzan de forma esporádica, aunque con una intensidad inédita.

Llegados a este punto, el lenguaje se muestra como el verdadero padre de la justicia (no el derecho) y la cita como aquello que castiga y salva. Por eso, esta debe liberarse del ámbito id́lico del sentido hermenéutico y ponerse en un punto de fuga ${ }^{17}$. La cita es la lucha contra la banalización del lenguaje al estallar el sentido y traer para el presente las obras que el espíritu humano ha producido como testimonio. Dichas obras son testigos de la naturaleza mentirosa de un derecho que se presenta defensor de la vida humana. Desnudar esa naturaleza es la tarea del monstruo: "El monstruo se encuentra entre nosotros como mensajero del más real humanismo" (Benjamin, 2010a, p. 376).

\section{CONCLUSIONES}

Porque el Mesías solo podrá entrar después de que la puerta se haya cerrado, es decir una vez que haya cesado la vigencia sin significado de la ley

(Agamben, 1998, p. 77).

En la trayectoria de este artículo se insiste en que al lenguaje le han arrebatado sus cualidades simbólicas, metafóricas y alegóricas. El lenguaje es objeto de una desposesión sistemática con la que el derecho contribuye y de la que se sirve para intensificar la red de culpabilidad que recubre la humanidad entera. Por lo tanto, solo en el lenguaje restaurado podrá concebirse la justicia y la capacidad de crear.

Lo antes expuesto permite plantear que el hombre total, el demonio y el monstruo, figuras utilizadas por Benjamin para ejercer su crítica al derecho, abren las puertas para la llegada del Mesías o, en otras palabras, para una política que, mediante la restauración del lenguaje, luche contra la red de culpabilidad del derecho. Mas debe enfatizarse que para Benjamin la redención mesiánica (Erlösung) no puede concretarse sin la rememoración (Eingedenken), pues la redención no se alcanza si se evade el deber moral de hacer justicia a los proyectos hundidos de los seres humanos que han cargado con el sufrimiento en la historia. Para precisar mejor la actividad de la rememoración, vale decir dos cosas al respecto: la primera es que por ella se mantiene vigente la deuda con la injusticia del pasado y la segunda resalta que la tensión entre historia y rememoración no puede clausurarse. Dicho de manera concreta, la historia, tal cual se ha recibido del historicismo, asume la injusticia como algo sellado y de lo que solo se

17 Es un procedimiento al que Benjamin llamará citar fuera de contexto. La preocupación no será lo que el autor supuestamente quiso decir en el pasado, sino lo que dice para el presente. Ahí radica la posibilidad de su conservación. 
puede informar cuantitativamente reduciendo los muertos a una cifra. Por su parte, la rememoración sostiene que la historia es más que una ciencia que pone un sello a la desdicha y pasa la página como si no pudiera hacer algo más. De lo que se trata es de usar la historia para dar un paso adelante y reparar el daño causado. Como lo advierte el mismo Benjamin, se trata de abrir los expedientes que la historiografía ha cerrado. Pero esto no ocurrirá mientras el derecho determine lo que es posible para los hombres. Ya se sabe que, por el derecho, lo humano queda reducido a mera vida natural, al borde de la subsistencia.

\section{REFERENCIAS}

Abadi, F. (2014). Conocimiento y redención en la filosofía de Walter Benjamin. Miño Dávila.

Agamben, G. (1998). Homo sacer. El poder soberano y la nuda vida. Pre-Textos.

Benjamin, W. (2009a). El narrador. En Obras. Libro II/vol. 2 (pp. 41-68). Abada.

Benjamin, W. (2009b). Karl Kraus. En Obras. Libro II/vol. 2 (pp. 234-235). Abada.

Benjamin, W. (2010a). Karl Kraus. En Obras. Libro II/vol. 1 (pp. 341-376). Abada.

Benjamin, W. (2010b). Sobre el lenguaje en cuanto tal y sobre el lenguaje del hombre. En Obras. Libro II/vol. 1 (pp. 144-162). Abada.

Benjamin, W. (2010c). La tarea del traductor. En Obras. Libro IV/vol.1 (pp. 9-22). Abada.

Benjamin, W. (2010d). Destino y Carácter. En Obras. Libro II/vol.1 (pp. 175-182). Abada.

Benjamin, W. (2010e). Hacia la crítica de la violencia. En Obras. Libro II/vol.1 (pp. 183-206). Abada.

Benjamin, W. (2010f). El origen del 'Trauerspiel alemán. En Obras. Libro I/vol. 1 (pp. 217-459). Abada.

Benjamin, W. (2010g). 'Las afinidades electivas' de Goethe. En Obras. Libro I/vol. 1 (pp. 129-216). Abada.

Benjamin, W. (2012). Sobre el concepto de historia. En Obras. Libro I/vol. 2 (pp. 303-318). Abada.

Benjamin, W. (2013). Obra de los pasajes. Obras. Libro V/vol. 1. Abada.

Benjamin, W. (2015). Obra de los pasajes. Obras. Libro V/vol. 2. Abada.

Bröcker, M. (2014). Lenguaje. En M. Opitz y E. Wizislat (eds.), Conceptos de Walter Benjamin (pp. 709759). Las Cuarenta.

Buck-Morss, S. (2001). Dialéctica de la mirada. Walter Benjamin y el proyecto de los Pasajes. La Balsa de la Medusa.

Butler, J. (2009). Performatividad, Precariedad y Políticas Sexuales. AIBR. Revista de Antropología Iberoamericana, 4(3), 321-336.

Butler, J. (2011). Violencia de Estado, guerra, resistencia. Por una nueva política de izquierda. Akal.

Cadava, E. (2014). Trazos de luz. Tesis sobre la fotografía de la historia. Palinodia.

Cohen, E. (1999). El silencio del nombre. Interpretación y pensamiento judío. Anthropos. 
De Man, P. (1989). La tarea del traductor de Walter Benjamin. Acta poética, 9(1-2), 257-294.

Echeverría, B. (2010). Siete aproximaciones a Walter Benjamin. Ediciones desde abajo.

Forster, R. (2014). La travesía del abismo. Mal y modernidad en Walter Benjamin. Fondo de Cultura Económica.

Foucault, M. (2002). Vigilar y castigar. Nacimiento de la prisión. Siglo XXI editores.

Galende, F. (2009). Walter Benjamin y la destrucción. Ediciones Metales Pesados.

Garcés-Gómez, J., y Escobar-García, B. (2010). Humanismos sin 'humanidad', a propósito de las filosofías renacentistas no platonizantes y las teorías de la formación. Revista Ratio Juris, 5(11), 45-67.

Hincapié-García, A. (2014). La 'cuestión' del mal y la Modernidad. A propósito de una lectura desde Walter Benjamin. Revista de Estudios Sociales, 50, 155-165.

Hincapié-García, A (2016a). 'Imaginación política' e impulso anti-narrativo. El retorno revolucionario de Walter Benjamin (1892-1940). En B. Escobar y A. Hincapié (eds.), Modernidad y política. Sobre la pregunta antropológica (pp. 43-70). Universidad Autónoma Latinoamericana.

Hincapié-García, A. (2016b). Formación y praxis pedagógica revolucionaria: los escritos de juventud de Marx y Benjamin. Andamios. Revista de Investigación Social, 13(32), 257-279.

Kant, I. (2003). Pedagogía. Akal.

Kozlarek, O. (2010). Walter Benjamin y América Latina: experiencias, descubrimientos y redescubrimientos. Revista Anthropos. Huellas del conocimiento, 225, 123-135.

Löwy, M. (1997). Redención y utopía. El judaísmo libertario en Europa central. Un estudio de afinidad electiva. Ediciones el cielo por asalto.

Löwy, M. (2015). Judíos heterodoxos. Romanticismo, mesianismo, utopía. Anthropos - Universidad Autónoma Metropolitana.

Mancera Martínez, F. (2005). Tiempo mesiánico. En B. Echeverría (comp.), La mirada del ángel. En torno a las Tesis sobre la historia de Walter Benjamin (pp. 143-151). Universidad Nacional Autónoma de México.

Marx, K. (2007). Manuscritos de economía y filosofía. Alianza.

Marx, K. (2008). Sobre la cuestión judía. En Escritos de juventud sobre el derecho. Textos 1837-1847 (pp. 171204). Barcelona: Anthropos.

Mate, R. (2006). Medianoche en la historia. Comentarios a las tesis de Walter Benjamin "Sobre el concepto de historia". Trotta.

Mosès, S. (1997). El Ángel de la historia. Rosenzweig, Benjamin, Scholem. Frónesis.

Nietzsche, F. (2016). Consideraciones intempestivas II. De la utilidad y los inconvenientes de la historia para la vida. En Obras completas. Volumen I. Escritos de juventud (pp. 705-758). Tecnos.

Piñeres-Sus, J. (2017). Lo humano como ideal regulativo. Imaginación antropológica, cultura, formación y antropología negativa. Universidad de Antioquia.

Rickert, H. (1971).Introducción a los problemas de la filosofía de la historia. Nova.

Romero Cuevas, J. (2010). Una crítica cultural materialista. Revista Anthropos. Huellas del conocimiento, 225, 85-99.

Sax, B. (2014). Walter Benjamin's Karl Kraus: Negation, Quotation, and Jewish Identity. Shofar, 32(3), 1-29. 
Sucasas, A. (2015). La shoah en Lévinas: un eco inaudible. Devenir el Otro.

Taub, E. (2008). La modernidad atravesada. Teología política y mesianismo. Miño Dávila.

Taub, E. (2013). Mesianismo y redención. Prolegómenos para una teología política judía. Miño Dávila.

Taub, E. (2015). Rememoración judía y tiempo mesiánico: sobre la potencia y la esperanza en el lenguaje. En A. Messina y E. Taub (eds.), Filosofía y mesianismo. Lenguaje, temporalidad y política (pp. 35-61). Metales Pesados.

Tobón-Tobón, M., y Mendieta-González, David. (2017). Los estados de excepción en el régimen constitucional colombiano, Opinión Jurídica, 16(31), 67-88.

Wohlfarth, I. (1989). Sobre algunos judíos en Benjamin. Acta poética, 9(1-2), 155-205.

Wohlfarth, I. (2016). Nietzsche y Benjamin: hombres del extranjero. En E. Cohen, E. R. Brondo, E. Santangelo y M. Santoveña (eds.), Walter Benjamin Fragmentos críticos (pp. 77-96). Universidad Nacional Autónoma de México. 